\title{
Estádio sucessional e fatores geográficos como determinantes da similaridade florística entre comunidades florestais no Planalto Atlântico, Estado de São Paulo, Brasil
}

\author{
Giselda Durigan ${ }^{1,7}$ Luís Carlos Bernacci², Geraldo Antonio Daher Correa Franco ${ }^{3}$, Géza de Faria Arbocz ${ }^{4}$, \\ Jean Paul Metzger ${ }^{5}$ e Eduardo Luís Martins Catharino ${ }^{6}$
}

Recebido em 12/12/2006. Aceito em 25/04/2007

\begin{abstract}
RESUMO - (Estádio sucessional e fatores geográficos como determinantes da similaridade florística entre comunidades florestais no Planalto Atlântico, Estado de São Paulo, Brasil). A análise das relações de similaridade florística entre comunidades geralmente conduz ao estabelecimento de padrões, condicionados por fatores diversos que determinam a ocorrência ou não das espécies em diferentes locais. Em busca de tais padrões, foram analisadas as relações de similaridade florística entre comunidades florestais localizadas na região do Planalto de Ibiúna, estado de São Paulo, Brasil. Incluíram-se na análise 21 fragmentos florestais e seis sítios em uma Reserva Florestal contínua, sendo que a composição florística e a estrutura da comunidade arbórea (DAP mínimo $5 \mathrm{~cm}$ ) em cada local foram amostradas pelo método de quadrantes. Aplicaram-se dois métodos de análises multivariadas: 1) Análise de Correspondência Destendenciada (DCA), com base no índice de similaridade de Sørensen; e 2) Divisão Hierárquica Dicotômica (TWINSPAN). A similaridade florística foi mais elevada entre comunidades em estádios sucessionais semelhantes, especialmente se estivessem geograficamente próximas. Há um gradiente florístico associado à latitude, indicando tratar-se de uma região de transição entre biomas. Nos sítios situados na face norte da região de estudo estão presentes espécies que também ocorrem no cerradão e em floresta estacional semidecidual, enquanto nos sítios situados na face sul prevalecem espécies características da floresta ombrófila densa.
\end{abstract}

Palavras-chave: análises multivariadas, ecótono, fitogeografia, Mata Atlântica, sucessão secundária

\begin{abstract}
Successional stage and geographic features determine floristic similarity among Atlantic Forest remnants, São Paulo State, Brazil). Analysis of floristic similarity relationships between plant communities can detect patterns of species occurrence and also explain conditioning factors. Searching for such patterns, floristic similarity relationships among Atlantic Forest sites situated at Ibiúna Plateau, São Paulo state, Brazil, were analyzed by multivariate techniques. Twenty one forest fragments and six sites within a continuous Forest Reserve were included in the analyses. Floristic composition and structure of the tree community (minimum dbh $5 \mathrm{~cm}$ ) were assessed using the point centered quarter method. Two methods were used for multivariate analysis: Detrended Correspondence Analysis (DCA) and Two-Way Indicator Species Analysis (TWINSPAN). Similarity relationships among the study areas were based on the successional stage of the community and also on spatial proximity. The more similar the successional stage of the communities, the higher the floristic similarity between them, especially if the communities are geographically close. A floristic gradient from north to south was observed, suggesting a transition between biomes, since northern indicator species are mostly heliophytes, occurring also in cerrado vegetation and seasonal semideciduous forest, while southern indicator species are mostly typical ombrophilous and climax species from typical dense evergreen Atlantic Forest.
\end{abstract}

Key words: Atlantic Forest, ecotone, multivariate analysis, phytogeography, secondary succession

\section{Introdução}

A Floresta Atlântica costuma ser dividida em dois grandes conjuntos florísticos, sendo um formado pelas florestas ombrófilas (densas e mistas), onde não há uma sazonalidade climática marcada, e outro formado por florestas estacionais semideciduais, em regiões com clara ocorrência de um período de déficit hídrico ao longo do ano (ver revisão de Oliveira Filho \& Fontes 2000). O Planalto Atlântico do Estado de São Paulo situa-se em condições de transição climática, havendo periodicidade no regime de chuvas, mas geralmente

\footnotetext{
1 Floresta Estadual de Assis, C. Postal 104, 19802-970 Assis, SP, Brasil

2 Instituto Agronômico de Campinas, Rua Barão de Itapura, 1481, C. Postal 28, 13020-902 Campinas, SP, Brasil

3 Instituto Florestal, Divisão de Dasonomia, Rua do Horto, 931, C. Postal 1322, 02377-000 São Paulo, SP, Brasil

4 IBAMA, SCEN, Trecho 2, Edifício Sede, C. Postal 09870, 70818-900 Brasília, DF, Brasil

5 Universidade de São Paulo, Instituto de Biociências, Rua do Matão, Travessa 14, 321, 05508-900 São Paulo, SP, Brasil

6 Instituto de Botânica, C. Postal 3005, 01061-970 São Paulo, SP, Brasil

7 Autor para correspondência: giselda@femanet.com.br
} 
sem ocorrência de déficit hídrico (Catharino et al. 2006). Nessas condições, a flora é naturalmente heterogênea e sua classificação bastante controversa (Ivanauskas et al. 2000). Este é, em particular, o caso da região do Planalto de Ibiúna, a oeste da cidade de São Paulo. Apesar das matas nessa região terem sido classificadas como pertencentes ao domínio da Floresta Ombrófila Densa (segundo a classificação de Veloso et al. 1991) em levantamentos cartográficos recentes (Kronka et al. 2005), diversos autores apontam para as características ecotonais das matas desse Planalto ou de regiões adjacentes (Eiten 1970; Nastri et al. 1992; Baitello et al. 1992; Salis et al. 1995; Aragaki \& Mantovani 1998; Catharino et al. 2006). Um dos exemplos mais surpreendentes dessa confluência de tipos florestais é a Floresta Nacional de Ipanema (Iperó, $\mathrm{SP})$, que, embora pertencente à região fitoecológica da Floresta Estacional Semidecidual, apresenta elementos de Floresta Ombrófila Densa e Mista e de Cerrado lato sensu (Albuquerque \& Rodrigues 2000).

Esse amplo espectro de variação ocorre em uma região muito restrita espacialmente, favorecendo assim a co-ocorrência de diferentes floras (Catharino et al. 2006). Já foi levantada a hipótese de que essa região tenha sido um refúgio alto-montano no Pleistoceno, servindo de abrigo para as diferentes floras em épocas de clima mais seco (Ab'Sáber 1992).

O presente estudo foi desenvolvido em áreas remanescentes do complexo vegetacional mencionado, visando, primeiramente, caracterizar a vegetação regional em relação às categorias fitoecológicas usualmente reconhecidas e explicar as semelhanças florísticas entre fragmentos remanescentes com base em uma série de atributos geográficos, na estrutura e no estádio sucessional da comunidade arbórea.

Partindo da premissa de que a flora arbórea varia ao longo do processo de sucessão secundária em florestas tropicais, esperava-se que comunidades em estádio sucessional semelhante fossem floristicamente semelhantes entre si, dentro da região em estudo. Considerando-se que a estrutura da comunidade também se modifica ao longo do processo sucessional, esperavase encontrar semelhança estrutural entre comunidades floristicamente semelhantes. Assim, testaram-se as seguintes hipóteses: 1) de que as comunidades arbóreas seriam mais semelhantes floristicamente quanto mais próximas estivessem no processo de sucessão secundária; 2) que estas teriam estruturas semelhantes e, alternativamente, 3) que apenas a proximidade espacial explicaria as relações de similaridade florística entre as comunidades estudadas.

\section{Material e métodos}

Área de estudo - Todos os sítios amostrados encontram-se em um quadrilátero de cerca de 23.000 ha, compreendido pela malha de coordenadas $23^{\circ} 38^{\prime}-23^{\circ} 50^{\prime}$ 'S e $46^{\circ} 53^{\prime}-47^{\circ} 13^{\prime} \mathrm{W}$, no Planalto de Ibiúna (municípios de Cotia e Ibiúna), cerca de $50 \mathrm{~km}$ a oeste da cidade de São Paulo, SP (Fig. 1). Esta região situa-se no alto das escarpas da Serra de Paranapiacaba e é sustentada, predominantemente, por rochas cristalinas pré-cambrianas (particularmente aquelas com alto grau metamórfico, tais como migmatitos ou rochas magmáticas, como o granito), cortadas por rochas intrusivas básicas e alcalinas mesozóico-terciárias (Almeida 1964). O relevo é composto por Mares de Morros, Morros com Serras Restritas, Serras Alongadas, Morrotes Alongados Paralelos e Planícies Aluviais (Ponçano et al. 1981), em altitudes variando de 860 a $1.052 \mathrm{~m}$. O clima predominante na região é caracterizado como temperado quente e úmido, do tipo $C f a$, de acordo com o sistema de Köppen (1948). A temperatura mensal máxima é de $27^{\circ} \mathrm{C}$, enquanto a mínima é de $11^{\circ} \mathrm{C}$. A ocorrência freqüente de ventos e neblinas caracteriza um clima relativamente frio para essas latitudes. A precipitação média anual é de cerca de 1.300 a $1.400 \mathrm{~mm}$, com variações sazonais. Os meses de abril

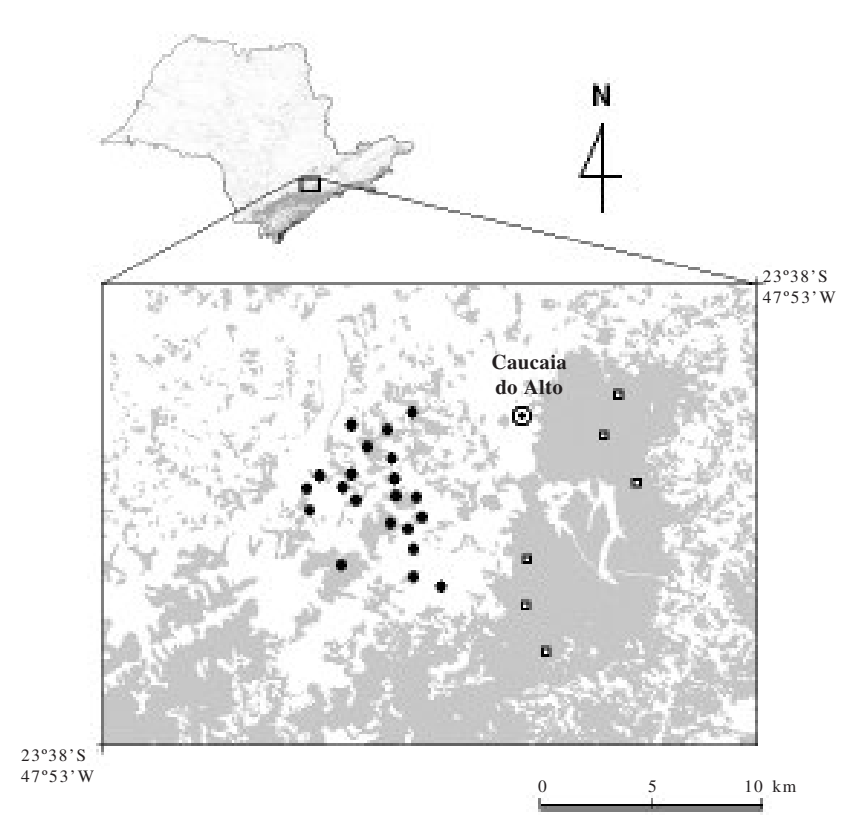

Figura 1. Localização da região (Planalto de Ibiúna, SP) e dos sítios de estudo na Reserva Florestal do Morro Grande e na paisagem fragmentada adjacente. Em cinza no mapa estão representadas as áreas com cobertura florestal. $(\bullet=$ Sítios de amostragem em paisagem fragmentada; $\square=$ Sítios de amostragem em floresta contínua (Reserva Florestal do Mato Grande)). 
a agosto são os de clima mais seco (precipitação média mensal entre 30 e $60 \mathrm{~mm}$ ) e mais frio (com as menores temperaturas médias).

A região de estudo abrange duas paisagens, sendo uma predominantemente florestal (a Reserva Florestal do Morro Grande) e a outra uma paisagem agrícola, que apresenta apenas $31 \%$ de cobertura florestal (Fig. 1). A Reserva cobre área de 10.870 ha, sendo 9.400 ha com florestas em estádios de regeneração mais avançados, provavelmente com mais de 80 anos de sucessão secundária (Metzger et al. 2006a). A paisagem fragmentada foi profundamente alterada pelo desmatamento durante séculos, visando o abastecimento da cidade de São Paulo, principalmente de lenha e carvão para a geração de energia, mas também com produtos agrícolas. Essa região é caracterizada por uma estrutura fundiária de pequenas propriedades, hoje principalmente voltadas para a produção hortifrutigranjeira. Os fragmentos florestais remanescentes na região têm tamanhos diversos, mas são geralmente pequenos (área inferior a 50 ha) e muitas vezes conectados entre si por corredores mais ou menos estreitos (40 a $60 \mathrm{~m}$ de largura), geralmente situados ao longo dos córregos. Raros desses fragmentos são remanescentes originais de uma floresta contínua préexistente, geralmente sendo resultado de processos recentes (20 a 80 anos) de sucessão secundária após corte raso. Assim, ao mosaico de pequenas propriedades rurais e seus respectivos históricos de desmatamento corresponde um mosaico de comunidades florestais de idades distintas.

Seleção dos sítios de estudo - Incluíram-se na análise 27 sítios de amostragem (Tab. 1), sendo 21 inseridos na paisagem fragmentada, em fragmentos de tamanho variável entre 2 e 275 ha, e seis sítios em trechos distintos da Reserva Florestal do Morro Grande, que tem área florestal contínua de 9.400 ha. Os sítios de estudo foram selecionados de forma a representar a mais ampla gama possível de tamanhos e graus de isolamento dos fragmentos na paisagem fragmentada, assim como trechos da Reserva em diferentes estádios de sucessão. O espaçamento entre os sítios amostrados na Reserva é similar ao espaçamento entre os fragmentos.

Caracterização florística e de estrutura da comunidade - Efetuou-se o levantamento fitossociológico em cada um dos sítios pelo método de quadrantes (Cottam \& Curtis 1956), modificado conforme o procedimento adotado em fragmentos florestais da região do Pontal do Paranapanema por Durigan et al. (2002).
A amostragem foi efetuada em blocos de 25 pontos, com distância mínima de $10 \mathrm{~m}$ entre pontos consecutivos, adotando-se o diâmetro mínimo à altura do peito (1,30 $\mathrm{m}$ acima do nível do solo) de $5 \mathrm{~cm}$. Em cada ponto foram amostrados quatro indivíduos, de modo que cada bloco era composto por 100 indivíduos. O número de blocos (de um a quatro) foi definido em função do tamanho de cada fragmento: nos sítios da Reserva do Morro Grande (códigos iniciando com a letra C) e nos maiores fragmentos (área mínima de 50 ha, códigos iniciando com a letra G), foram dispostos quatro blocos; nos fragmentos de tamanho intermediário ( 5 a 40 ha, códigos iniciando com a letra M), foram estabelecidos dois a três blocos e nos fragmentos pequenos ( 2 a 5 ha, códigos iniciando com a letra $\mathrm{P}$ ), o levantamento foi feito em um único bloco. No caso da Reserva do Morro Grande, foram amostrados seis sítios distintos, cada um com quatro blocos. A distância entre blocos dentro de cada sítio foi fixada em $200 \mathrm{~m}$.

Visando eliminar as imprecisões do método de quadrantes nas estimativas dos valores absolutos de densidade e dominância, conforme o método utilizado por Durigan et al. (2002), não foram efetuadas as medições de distâncias árvore-ponto, convencionalmente utilizadas no método de quadrantes para estimativa de densidade. Para obtenção da densidade total da comunidade em cada bloco, foram contabilizadas as árvores (acima do critério de inclusão) presentes em parcelas de $100 \mathrm{~m}^{2}(25 \times 4 \mathrm{~m})$, sistematicamente distribuídas ao longo dos transectos, uma a cada cinco pontos de amostragem. A partir deste valor de densidade total da comunidade, em substituição à estimativa baseada na distância média árvore-ponto, obteve-se a estimativa de densidade absoluta de cada espécie, pelo mesmo procedimento adotado no método de quadrantes convencional, ou seja, a partir dos valores de densidade relativa das espécies. Cada árvore foi identificada, tendo sido medido o DAP com suta e estimada a altura.

Como ferramenta auxiliar para a interpretação dos resultados, as espécies foram submetidas à classificação segundo grupos sucessionais (pioneiras, secundárias iniciais, secundárias tardias ou umbrófilas), com base em Kageyama \& Viana (1992) e Gandolfi et al. (1995).

Análises de ordenação - Foram efetuadas análises multivariadas dos dados florísticos categóricos (presença e ausência) e quantitativos (abundância) das espécies arbóreas presentes em cada um dos 27 sítios 
Tabela 1. Atributos geográficos e de estrutura da comunidade dos 27 sítios de amostragem (21 fragmentos e seis sítios na Reserva Florestal do Morro Grande) na região do Planalto de Ibiúna, estado de São Paulo. DAP: diâmetro do tronco à altura do peito (1,3 m acima do nível do solo).

\begin{tabular}{|c|c|c|c|c|c|c|c|c|c|c|c|}
\hline $\begin{array}{l}\text { Código do } \\
\text { sítio }\end{array}$ & lo Paisagem & $\begin{array}{l}\text { Latitude } \\
\text { (UTM) }\end{array}$ & $\begin{array}{l}\text { Longitude } \\
\text { (UTM) }\end{array}$ & $\begin{array}{l}\text { Altitude } \\
\text { (m) }\end{array}$ & $\begin{array}{c}\text { Área } \\
\text { (ha) }\end{array}$ & $\begin{array}{c}\text { Densidade } \\
\left(\text { árovres.ha }{ }^{-1}\right)\end{array}$ & $\begin{array}{c}\text { Área I } \\
\text { basal } \\
\left(\mathrm{m}^{2} \cdot \mathrm{ha}^{-1}\right)\end{array}$ & $\begin{array}{l}\text { DAP máx. } \\
\quad(\mathrm{cm})\end{array}$ & $\begin{array}{l}\text { Altura } \\
\text { máxima } \\
\text { das } \\
\text { árvores } \\
\quad(\mathrm{m})\end{array}$ & $\begin{array}{l}\text { Espécies } \\
\text { pioneiras e } \\
\text { secundárias } \\
\text { iniciais } \\
\text { (\% indivíduos) }\end{array}$ & $\begin{array}{c}\text { Espécies } \\
\text { umbrófilas e } \\
\text { secundárias } \\
\text { tardias } \\
\text { (\% indivíduos) }\end{array}$ \\
\hline $\mathrm{C} 1$ & Florestal & 7380290 & 300225 & 889 & 9400,4 & 3005 & 48 & 65 & 25 & 37 & 58 \\
\hline $\mathrm{C} 2$ & Florestal & 7378046 & 300475 & 909 & 9400,4 & 2445 & 36 & 75 & 20 & 46 & 51 \\
\hline $\mathrm{C} 3$ & Florestal & 7375950 & 301659 & 930 & 9400,4 & 2130 & 32 & 50 & 26 & 47 & 51 \\
\hline $\mathrm{C} 4$ & Florestal & 7371318 & 295710 & 916 & 9400,4 & 2244 & 79 & 118 & 30 & 24 & 75 \\
\hline $\mathrm{C} 5$ & Florestal & 7369012 & 295489 & 915 & 9400,4 & 2005 & 54 & 108 & 25 & 34 & 65 \\
\hline C6 & Florestal & 7366857 & 296534 & 914 & 9400,4 & 2522 & 62 & 94 & 30 & 49 & 50 \\
\hline G1 & Fragmentada & 7370622 & 286817 & 974 & 274,3 & 1995 & 30 & 49 & 27 & 66 & 34 \\
\hline G2 & Fragmentada & 7373242 & 288685 & 961 & 175,1 & 2610 & 31 & 39 & 31 & 62 & 37 \\
\hline G3 & Fragmentada & 7374650 & 289693 & 951 & 52,2 & 2156 & 30 & 45 & 24 & 69 & 31 \\
\hline G4 & Fragmentada & 7375737 & 286664 & 933 & 53,1 & 2030 & 27 & 35 & 20 & 75 & 24 \\
\hline G5 & Fragmentada & 7377212 & 287817 & 948 & 99,4 & 1825 & 32 & 48 & 22 & 58 & 42 \\
\hline M1 & Fragmentada & 7378521 & 286631 & 904 & 18,3 & 2273 & 34 & 54 & 18 & 65 & 34 \\
\hline M2 & Fragmentada & 7378204 & 288313 & 924 & 47,9 & 1900 & 32 & 67 & 17 & 76 & 24 \\
\hline M3 & Fragmentada & 7375697 & 288660 & 919 & 14,1 & 2310 & 34 & 50 & 17 & 76 & 23 \\
\hline M4 & Fragmentada & 7373581 & 290200 & 953 & 18,8 & 1967 & 32 & 44 & 22 & 67 & 32 \\
\hline M5 & Fragmentada & 7374705 & 288751 & 932 & 12,9 & 2030 & 28 & 45 & 20 & 47 & 52 \\
\hline M6 & Fragmentada & 7374241 & 284420 & 951 & 28,9 & 1407 & 27 & 95 & 20 & 47 & 52 \\
\hline M7 & Fragmentada & 7375650 & 284504 & 927 & 14,0 & 1690 & 29 & 51 & 16 & 46 & 52 \\
\hline M8 & Fragmentada & 7376248 & 285796 & 884 & 31,2 & 1920 & 27 & 53 & 20 & 71 & 29 \\
\hline $\mathrm{P} 1$ & Fragmentada & 7378095 & 289206 & 905 & 4,6 & 2980 & 27 & 37 & 15 & 39 & 61 \\
\hline $\mathrm{P} 2$ & Fragmentada & 7376493 & 288729 & 886 & 2,0 & 2880 & 43 & 36 & 16 & 92 & 8 \\
\hline P3 & Fragmentada & 7373226 & 289771 & 971 & 3,6 & 1940 & 36 & 37 & 16 & 87 & 13 \\
\hline $\mathrm{P} 4$ & Fragmentada & 7371902 & 290510 & 928 & 5,5 & 1720 & 21 & 37 & 22 & 29 & 64 \\
\hline P5 & Fragmentada & 7369936 & 291517 & 931 & 5,0 & 1680 & 35 & 87 & 22 & 21 & 78 \\
\hline P6 & Fragmentada & 7372549 & 289560 & 930 & 4,7 & 2200 & 31 & 45 & 18 & 66 & 34 \\
\hline $\mathrm{P} 7$ & Fragmentada & 7375729 & 287155 & 916 & 3,8 & 2100 & 25 & 31 & 17 & 95 & 5 \\
\hline P8 & Fragmentada & 7376221 & 287161 & 927 & 4,6 & 1560 & 33 & 85 & 20 & 80 & 20 \\
\hline
\end{tabular}

de amostragem. Essas análises, descritas a seguir, foram executadas utilizando-se o Programa PCORD (McCune \& Mefford 1999).

A ordenação dos dados por Análise de Correspondência Destendenciada (DCA, Detrended Correspondence Analysis, Hill \& Gauch 1980) foi efetuada utilizando-se a matriz de densidade absoluta das espécies nos 27 sítios em estudo, tendo sido consideradas apenas as espécies com quatro ou mais ocorrências (179 espécies), uma vez que espécies raras não contribuem para a ordenação de sítios por similaridade florística. Previamente, havia sido testada a mesma análise considerando-se a abundância das espécies por bloco, mas como os padrões observados foram semelhantes, não havendo influência do maior esforço amostral nos fragmentos maiores, optou-se por apresentar apenas a análise por sítio de estudo.
De forma complementar, principalmente para definir as espécies indicadoras dos grupos florísticos, utilizou-se também a divisão hierárquica dicotômica por TWINSPAN (Two-Way Indicator Species Analysis; Hill 1979), a partir da matriz composta pelas 179 espécies e sua ocorrência nos 27 locais.

Variáveis geográficas e de estrutura da comunidade Cada sítio de estudo foi caracterizado a partir de variáveis geográficas e de atributos relacionados com a estrutura da comunidade (Tab. 1). Os dados de latitude, longitude e altitude foram obtidos por cartas topográficas em escala 1:10.000, publicadas pelo Governo do Estado de São Paulo (SEP 1979). Essas variáveis foram escolhidas para verificar se a proximidade entre sítios ou a altitude são fatores determinantes da similaridade florística entre comunidades. 
A área de cada fragmento foi calculada a partir de interpretação de fotografias aéreas obtidas em abril/2000, na escala de 1:10.000. O tamanho de cada sítio foi utilizado nas análises para testar uma possível influência dessa variável sobre a semelhança florística entre os sítios.

Os parâmetros estruturais da vegetação considerados nas análises foram: densidade e área basal por hectare (obtidas a partir da média dos blocos para cada área), o maior DAP (diâmetro do tronco à altura do peito) amostrado e a altura máxima dentre as árvores amostradas. Da mesma forma que se calculam a densidade e a dominância absolutas pelo método de quadrantes convencional, obtiveram-se os valores absolutos a partir dos valores relativos, por regra de três a partir da densidade total da comunidade (estimada pela média das parcelas de densidade de cada bloco). Essas variáveis estruturais foram selecionadas para testar a hipótese de que comunidades estruturalmente semelhantes fossem floristicamente semelhantes.

Para verificar se as comunidades florestais são mais semelhantes quanto mais próximas estiverem no processo de sucessão secundária, considerou-se a abundância relativa de espécies por categoria sucessional, agrupando-se as espécies intolerantes (pioneiras e secundárias iniciais) e as tolerantes à sombra (umbrófilas e secundárias tardias). Partiu-se da premissa de que maior proporção de espécies arbóreas tolerantes à sombra em florestas tropicais reflete estádio sucessional mais avançado.

Os atributos geográficos e de estrutura da comunidade de cada floresta estudada foram submetidos a análises de correlação com os eixos resultantes da DCA, visando explicar as variáveis que determinam as relações de similaridade entre sítios.

\section{Resultados}

Para um total de 7.400 árvores amostradas, foram identificadas 362 espécies, pertencentes a 171 gêneros de 71 famílias (dados detalhados do estudo florístico em Bernacci et al. 2006). Dentre todas as espécies amostradas, 179 ocorreram em pelo menos quatro sítios (Tab. 2) e estas foram utilizadas nas análises do presente estudo.

A densidade da floresta variou desde 1.407 até 3.005 árvores por hectare, com os maiores valores geralmente associados à floresta contínua. A área basal variou de 21 a $79 \mathrm{~m}^{2} \cdot \mathrm{ha}^{-1}$, sendo que, dos seis maiores valores, cinco correspondem às áreas de amostragem no interior da Reserva do Morro Grande, ou seja, na floresta não fragmentada. O porte das maiores árvores também tendeu a ser maior na floresta contínua, em comparação com os fragmentos. Porém, essas tendências de agrupamento das áreas pelas características estruturais da comunidade arbórea na floresta contínua ou na paisagem fragmentada (Tab. 1) não corresponderam a semelhanças florísticas.

Os diagramas resultantes da ordenação por DCA (Fig. 2) mostram, de modo geral, os sítios regularmente dispersos ao longo dos eixos, não indicando fortes padrões fitogeográficos dentro da região de abrangência do projeto. O eixo 1 explica $14,15 \%$ da variação, o eixo $2,9,23 \%$ e o eixo 3 apenas $4,78 \%$.

Com base nas análises de correlação entre os atributos de cada área de estudo e destas com os eixos da DCA (Tab. 3), verifica-se que as relações de similaridade florística entre os sítios se estabelecem principalmente em função do estádio sucessional da comunidade, representado na matriz dos atributos pela porcentagem de espécies intolerantes (pioneiras e secundárias iniciais) e tolerantes à sombra (secundárias tardias e climácicas), que são os dois únicos atributos que aparecem com valores altamente significativos de correlação com dois dos eixos da DCA (1 e 2). Outros fatores : altitude, latitude, longitude, tamanho do fragmento, área basal, altura e DAP máximo das árvores, explicam a posição dos sítios em relação a apenas um dos eixos, de modo que nem sempre resultam em proximidade entre as áreas nos gráficos de ordenação. A esperada correlação entre o estádio sucessional da comunidade e sua estrutura (densidade, altura das árvores e área basal) não foi observada nos sítios estudados (Tab. 1). A densidade e o porte das árvores parecem ser mais fortemente dependentes de fatores outros que não aqueles relacionados com a sucessão secundária ou a composição florística, tais como a condição de fragmentação ou a disponibilidade de água e nutrientes no solo (estes não analisados aqui), de modo que comunidades em estádios sucessionais semelhantes podem ser consideravelmente diferentes em sua estrutura.

No gráfico da ordenação com os dois primeiros eixos da DCA (Fig. 2A), os sítios em que a comunidade se apresenta menos desenvolvida no processo sucessional (M2, P2, P7, P8), com alta porcentagem de indivíduos de espécies pioneiras ou secundárias iniciais, tendem a aparecer à direita da figura, enquanto na face oposta colocam-se os sítios de floresta mais 
Tabela 2. Espécies arbóreas amostradas em pelo menos quatro locais de amostragem de florestas na região do Planalto de Ibiúna, SP, utilizadas nas análises multivariadas do presente estudo.

\begin{tabular}{|c|c|}
\hline Família/Espécie & Família/Espécie \\
\hline AGAVACEAE & ERYTHROXYLACEAE \\
\hline Cordyline spectabilis Kunth \& Bouché & Erythroxylum argentinum O.E. Schulz \\
\hline ANACARDIACEAE & EUPHORBIACEAE \\
\hline Lithraea molleoides (Vell.) Engl. & Alchornea triplinervia (Spreng.) Müll.Arg. \\
\hline Schinus terebinthifolius Raddi & Croton floribundus Spreng. \\
\hline Tapirira guianensis Aubl. & Pera glabrata (Schott) Poepp. ex Baill. \\
\hline ANNONACEAE & Sapium glandulosum (L.) Morong \\
\hline Duguetia lanceolata A. St.-Hil. & Sebastiania brasiliensis Spreng. \\
\hline Guatteria australis A. St.-Hil. & S. commersoniana (Baill.) L.B. Sm. \& Downs \\
\hline G. cf. nigrescens Mart. & FABACEAE \\
\hline Rollinia sericea (R.E. Fr.) R.E. Fr. & Abarema langsdorffii (Benth.) Barneby \& J.W. Grimes \\
\hline R. sylvatica (A. St.-Hil.) Mart. & Anadenanthera colubrina (Vell.) Brenan \\
\hline APOCYNACEAE & Andira anthelmia (Vell.) J.F. Macbr. \\
\hline Aspidosperma olivaceum Müll.Arg. & Copaifera trapezifolia Hayne \\
\hline AQUIFOLIACEAE & Dalbergia brasiliensis Vogel \\
\hline Ilex amara (Vell.) Loes. & Inga marginata Willd. \\
\hline I. brevicuspis Reissek & I. sessilis (Vell.) Mart. \\
\hline I. paraguariensis A.St.-Hil. & Lonchocarpus subglaucescens Mart. ex Benth. \\
\hline I. theezans var. warmingiana Loes. & Machaerium aculeatum Raddi \\
\hline ARALIACEAE & M. nictitans (Vell.) Benth. \\
\hline Didymopanax angustissimus Marchal & M. vestitum Vogel \\
\hline ARECACEAE & M. villosum Vogel \\
\hline Euterpe edulis Mart. & Ormosia dasycarpa Jacks. \\
\hline Lytocaryum hoehnei (Burret) Toledo & Piptadenia gonoacantha (Mart.) J.F. Macbr. \\
\hline Syagrus romanzoffiana (Cham.) Glassman & P. paniculata var. aculeata Bukart \\
\hline ASTERACEAE & Sclerolobium denudatum Vogel \\
\hline Baccharis schultzii Baker & Senna multijuga (Rich.) H.S. Irwin \& Barneby \\
\hline Dasyphyllum tomentosum (Spreng.) Cabrera & Zollernia ilicifolia (Brongn.) Vogel \\
\hline Gochnatia polymorpha (Less.) Cabrera & FLACOURTIACEAE \\
\hline Piptocarpha angustifolia Dusén ex Malme & Casearia decandra Jacq. \\
\hline P. axillaris (Less.) Baker & C. obliqua Spreng. \\
\hline P. regnelii (Sch.Bip.) Cabrera & C. sylvestris $\mathrm{Sw}$. \\
\hline Raulinoreitzia leptophlebia (B.L. Rob.) R.M. King \& H. Rob. & Xylosma ciliatifolia (Clos) Eichler \\
\hline Vernonia diffusa Less. & X. pseudosalzmanii Sleumer \\
\hline BIGNONIACEAE & LAURACEAE \\
\hline Jacaranda puberula Cham. & Cinnamomum pseudoglaziovii Lorea-Hern. \\
\hline Tabebuia chrysotricha (Mart. ex A.DC.) Standl. & Cryptocarya moschata Nees \\
\hline BOMBACACEAE & C. saligna $\mathrm{Mez}$ \\
\hline Pseudobombax grandiflorum (Cav.) A. Robyns & Endlicheria paniculata (Spreng.) J.F. Macbr. \\
\hline BORAGINACEAE & Nectandra barbellata Coe-Teix. \\
\hline Cordia sellowiana Cham. & N. grandiflora Nees \\
\hline CELASTRACEAE & N. oppositifolia Nees \\
\hline Maytenus evonymoides Reissek & Ocotea bicolor Vattimo-Gil \\
\hline M. robusta Reissek & O. catharinensis $\mathrm{Mez}$ \\
\hline CHRYSOBALANACEAE & O. corymbosa (Meisn.) Mez \\
\hline Hirtella hebeclada Moric. ex DC. & O. daphnifolia (Meisn.) Mez \\
\hline CLETHRACEAE & O. dispersa (Nees) Mez \\
\hline Clethra scabra Pers. & O. elegans $\mathrm{Mez}$ \\
\hline CUNONIACEAE & O. glaziovii Mez \\
\hline Lamanonia ternata Vell. & O. odorifera (Vell.) Rohwer \\
\hline CYATHEACEAE & O. porosa (Nees) Barroso \\
\hline Alsophila setosa Kaulf. & O. puberula (Rich.) Nees \\
\hline Cyathea atrovirens (Langsd. \& Fisch.) Domin & O. pulchella (Nees) Mez \\
\hline C. delgadii Sternb. & O. silvestris Vattimo-Gil \\
\hline ELAEOCARPACEAE & Persea wildenovii Kosterm. \\
\hline
\end{tabular}


Tabela 2 (continuação)

\begin{tabular}{|c|c|}
\hline Família/Espécie & Família/Espécie \\
\hline LECITHIDACEAE & OCHNACEAE \\
\hline Cariniana estrellensis (Raddi) Kuntze & Ouratea vaccinioides (A. St.-Hil. \& Tul.) Engl. \\
\hline MALPIGUIACEAE & OLACACEAE \\
\hline Byrsonima ligustrifolia A. Juss. & Heisteria silvianii Schwacke \\
\hline MELASTOMATACEAE & OLEACEAE \\
\hline Miconia budlejoides Triana & Chionanthus filiformis (Vell.) P.S. Green \\
\hline M. cabussu Hoehne & PHYTOLACCACEAE \\
\hline M. inconspicua Miq. & Seguieria floribunda Benth. \\
\hline M. ligustroides (DC.) Naudin & POLYGONACEAE \\
\hline M. sellowiana Naudin & Coccoloba warmingii Meisn. \\
\hline M. valtherii Naudin & PROTEACEAE \\
\hline Tibouchina pulchra (Cham.) Cogn. & Roupala montana Aubl. \\
\hline MELIACEAE & ROSACEAE \\
\hline Cabralea canjerana (Vell.) Mart. & Prunus myrtifolia (L.) Urb. \\
\hline Cedrela odorata $\mathrm{L}$. & RUBIACEAE \\
\hline MONIMIACEAE & Alibertia cf. myrciifolia K. Schum. \\
\hline Mollinedia oligantha Perkins & A. concolor (Cham.) K. Schum. \\
\hline M. uleana Perkins & Amaioua intermedia Mart. \\
\hline MORACEAE & Bathysa meridionalis L.B. Sm. \& Downs \\
\hline Brosimum glaziovii Taub. & Coussarea contracta var. panicularis Müll. Arg. \\
\hline Ficus enormis (Mart. ex Miq.) Miq. & Faramea montevidensis (Cham. \& Schltdl.) DC. \\
\hline Sorocea bonplandii (Baill.) W.C. Burger, Lanj. \& Wess. Boer & Posoqueria latifolia (Rudge) Roem. \& Schult. \\
\hline MYRSINACEAE & Psychotria cf. longipes Müll. Arg. \\
\hline Rapanea gardneriana (A. DC.) Mez & P. suterella Müll. Arg. \\
\hline R. umbellata (Mart.) Mez & Rudgea gardenioides (Cham.) Müll. Arg. \\
\hline MYRTACEAE & R. jasminoides (Cham.) Müll. Arg. \\
\hline & RUTACEAE \\
\hline Campomanesia eugenioides (Cambess.) D. Legrand & Esenbeckia grandiflora Mart. \\
\hline C. guaviroba (DC.) Kiaersk. & Zanthoxylum rhoifolium Lam. \\
\hline C. guazumifolia (Cambess.) O. Berg & SAPINDACEAE \\
\hline C. xanthocarpa $\mathrm{O}$. Berg & Allophylus edulis (A. St.-Hil., A. Juss. \& Cambess.) Radlk. \\
\hline $\begin{array}{l}\text { Eugenia cerasiflora } \text { Miq. } \\
\text { Euntion }\end{array}$ & Cupania oblongifolia Mart. \\
\hline $\begin{array}{l}\text { Eugenia cerasiflora } \text { dodonaeifolia Cambess. } \\
\text { E. }\end{array}$ & C. vernalis Cambess. \\
\hline E. excelsa O. Berg & Matayba elaeagnoides Radlk. \\
\hline $\begin{array}{l}\text { E. excelsa } \mathrm{U} \text {. Berg } \\
\text { Evolucrata } \mathrm{DC} \text {. }\end{array}$ & M. guianensis Aubl. \\
\hline $\begin{array}{l}\text { E. involucrata DC. } \\
\text { E. mosenii (Kausel) Sobral }\end{array}$ & M. juglandifolia (Cambess.) Radlk. \\
\hline $\begin{array}{l}\text { E. mosenii (Kausel) Sobral } \\
\text { E. pluriflora } \mathrm{DC} \text {. }\end{array}$ & SAPOTACEAE \\
\hline $\begin{array}{l}\text { E. pluriflora } \mathrm{DC} \text {. } \\
\text { E. sonderiana } \mathrm{O} \text {. Berg }\end{array}$ & Chrysophyllum marginatum (Hook. \& Arn.) Radlk. \\
\hline $\begin{array}{l}\text { E. sonderiana } \mathrm{O} \text {. Berg } \\
\text { E. speciosa Cambess. }\end{array}$ & Pouteria bullata (S. Moore) Baehni \\
\hline $\begin{array}{l}\text { E. speciosa } \text { Cambess. } \\
\text { E. stictosepala Kiaersk. }\end{array}$ & P. caimito (Ruiz \& Pav.) Radlk. \\
\hline & SIMAROUBACEAE \\
\hline Gomidesia anacardiifolia (Gardner) O. Berg & Picramnia cf. ramiflora Planch. \\
\hline G. hebepetala (DC.) O. Berg. & P. parvifolia Engl. \\
\hline G. tijucensis (Kiaersk.) D. Legrand & SOLANACEAE \\
\hline Marlierea cf. reitzii D. Legrand & Solanum bullatum Vell. \\
\hline Myrceugenia rufescens (DC.) D. Legrand \& Kausel & S. cinnamomeum Sendtn. \\
\hline Myrcia cf. citrifolia (Aubl.) Urb. & S. pseudoquina A. St.-Hil. \\
\hline M. cf. laruotteana Cambess. & S. swartzianum Roem. \& Schult. \\
\hline M. fallax (Rich.) DC. & STYRACACEAE \\
\hline M. multiflora (Lam.) DC. & Styrax leprosus Hook. \& Arn. \\
\hline Myrcia sp.1 & SYMPLOCACEAE \\
\hline M. venulosa DC. & Symplocos glanduloso-marginata Hoehne \\
\hline Myrciaria floribunda (H. West ex Willd.) O. Berg & S. tetrandra Mart. ex Miq. \\
\hline Pimenta pseudocaryophyllus (Gomes) Landrum & S. uniflora (Pohl) Benth. \\
\hline Psidium cattleyanum Sabine & S. variabilis Mart. \\
\hline NYCTAGINACEAE & VOCHYSIACEAE \\
\hline Guapira areolata (Heimerl) Lundell & Vochysia magnifica Warm. \\
\hline G. opposita (Vell.) Reitz & V. tucanorum Mart. \\
\hline
\end{tabular}


madura (C4, C5, M6, M7, P4, P5), com alta porcentagem de indivíduos de espécies umbrófilas ou secundárias tardias. Ao considerarmos o primeiro e o terceiro eixos na análise (Fig. 2B), reforça-se o estádio sucessional da comunidade como fator determinante da proximidade entre os sítios, mas a latitude e a longitude aparecem como fatores adicionais gerando similaridade, de modo que as áreas se distribuem ao longo dos eixos segundo a proximidade geográfica entre elas.

A análise da divisão hierárquica dos grupos floristicamente semelhantes por TWINSPAN (Fig. 3) mostra que as semelhanças florísticas se estabelecem principalmente em função da posição geográfica dos sítios de estudo : latitude no primeiro nível de divisão e longitude no segundo. A análise dos grupos aponta também para uma confirmação dos resultados da DCA, pois tendem a se agrupar sítios que se assemelham do ponto de vista do estádio sucessional da comunidade. Todavia, ao apresentar as espécies preferenciais dos dois grandes grupos, a classificação dicotômica por TWINSPAN possibilita uma leitura mais acurada das especificidades florísticas das áreas
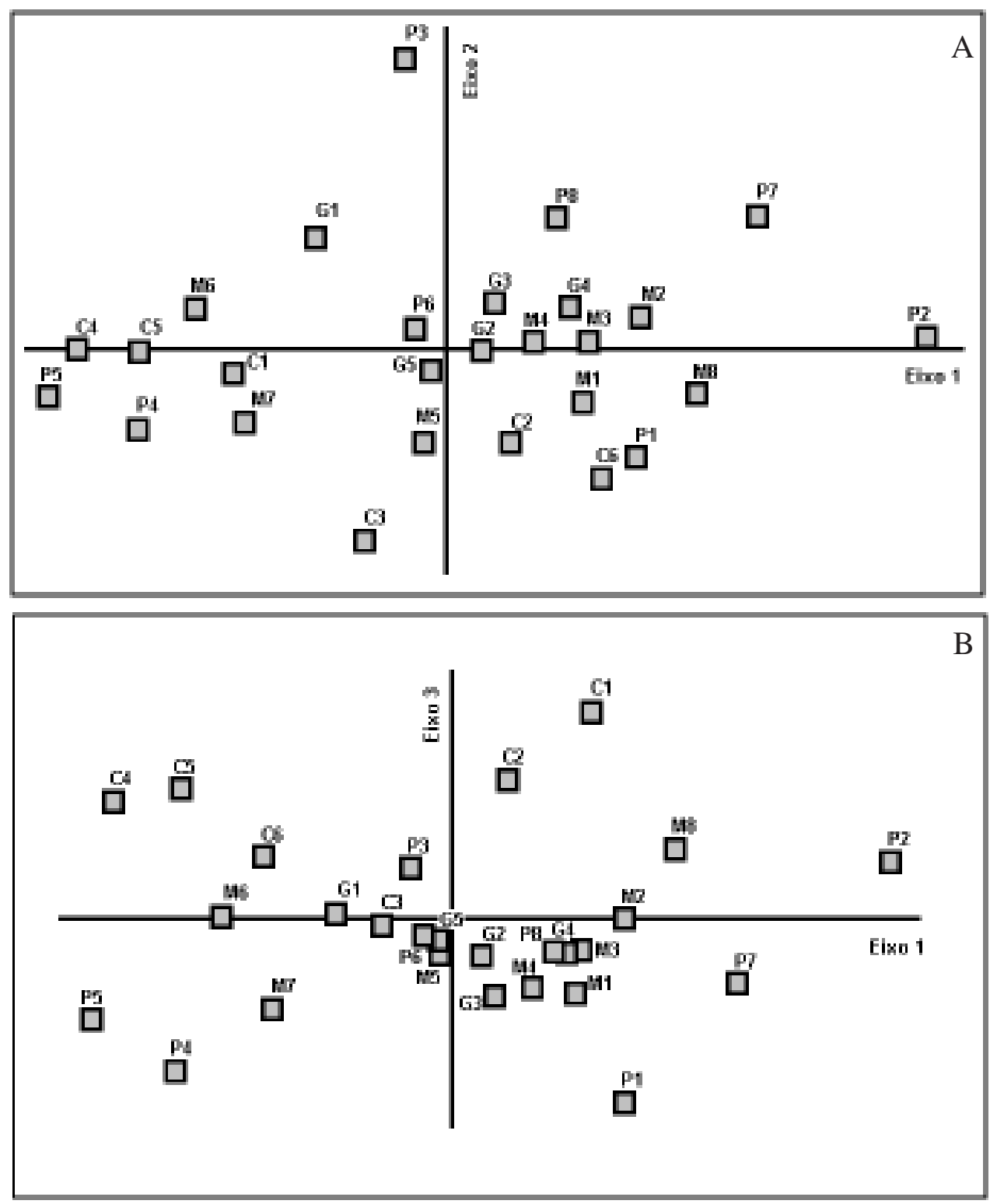

Figura 2. Ordenação dos 27 sítios florestais amostrados na região do Planalto de Ibiúna (SP), a partir do primeiro (horizontal) e terceiro (vertical) eixos de uma Análise de Correspondência Destendenciada. A. Eixos 1 e 2. B. Eixos 1 e 3. Os códigos completos dos sítios são apresentados na Tab. 1. C - sítios localizados no interior da floresta contínua, Reserva Florestal do Morro Grande; G - fragmentos grandes (área superior a 50 ha); M - fragmentos médios ( 5 a 40 ha); P- fragmentos pequenos ( 2 a 5 ha). 
Tabela 3. Correlação entre os atributos geográficos e estruturais da floresta e a posição dos sítios de estudo ao longo dos eixos 1 , 2 e 3 da DCA (Análise de Correspondência Destendenciada). r - coeficiente de correlação. S - probabilidade de significância. n.s. - valores não significativos. Em negrito, valores altamente significativos.

\begin{tabular}{|c|c|c|c|c|c|c|}
\hline \multirow[t]{2}{*}{ Atributos geográficos e estruturais da floresta } & \multicolumn{2}{|c|}{ Eixo 1} & \multicolumn{2}{|c|}{ Eixo 2} & \multicolumn{2}{|c|}{ Eixo 3} \\
\hline & $\mathrm{r}$ & S & $\mathrm{r}$ & $\mathrm{S}$ & $\mathrm{r}$ & $\mathrm{S}$ \\
\hline Densidade (árvores ha-1) & 0,461 & $5 \%$ & $-0,313$ & n.s. & 0,278 & n.s. \\
\hline Latitude (UTM) & 0,702 & $1 \%$ & $-0,234$ & n.s. & $-0,008$ & n.s. \\
\hline Longitude (UTM) & $-0,223$ & n.s. & $-0,434$ & $5 \%$ & $\mathbf{0 , 5 5 3}$ & $1 \%$ \\
\hline Altitude (m) & $-0,381$ & n.s. & $\mathbf{0 , 5 0 0}$ & $1 \%$ & $-0,298$ & n.s. \\
\hline Área (ha) & $-0,311$ & n.s. & $-0,382$ & $5 \%$ & 0,698 & $1 \%$ \\
\hline Área basal média $\left(\mathrm{m}^{2} \cdot \mathrm{ha}^{-1}\right)$ & $-0,327$ & n.s. & $-0,032$ & n.s. & 0,637 & $1 \%$ \\
\hline DAP máximo $(\mathrm{cm})$ & $-0,577$ & $1 \%$ & $-0,077$ & n.s. & 0,486 & n.s. \\
\hline Altura máxima das árvores (m) & $-0,490$ & $1 \%$ & $-0,180$ & n.s. & 0,340 & n.s. \\
\hline $\begin{array}{l}\text { Porcentagem de indivíduos de espécies } \\
\text { pioneiras e secundárias iniciais }\end{array}$ & 0,744 & $1 \%$ & 0,627 & $1 \%$ & $-0,052$ & n.s. \\
\hline $\begin{array}{l}\text { Porcentagem de indivíduos de espécies } \\
\text { umbrófilas e secundárias tardias }\end{array}$ & $-\mathbf{- 0 , 7 5 0}$ & $1 \%$ & $-0,612$ & $1 \%$ & 0,045 & n.s. \\
\hline
\end{tabular}

de estudo, trazendo à luz explicações adicionais para os resultados obtidos.

No primeiro nível de divisão (autovalor 0,3026) surgem, com clareza, dois grandes grupos. No primeiro grupo, encontram-se 18 sítios situados do centro para o norte da região de estudo, independentemente de estarem na paisagem fragmentada ou na floresta contínua. Ao se analisarem as espécies preferenciais

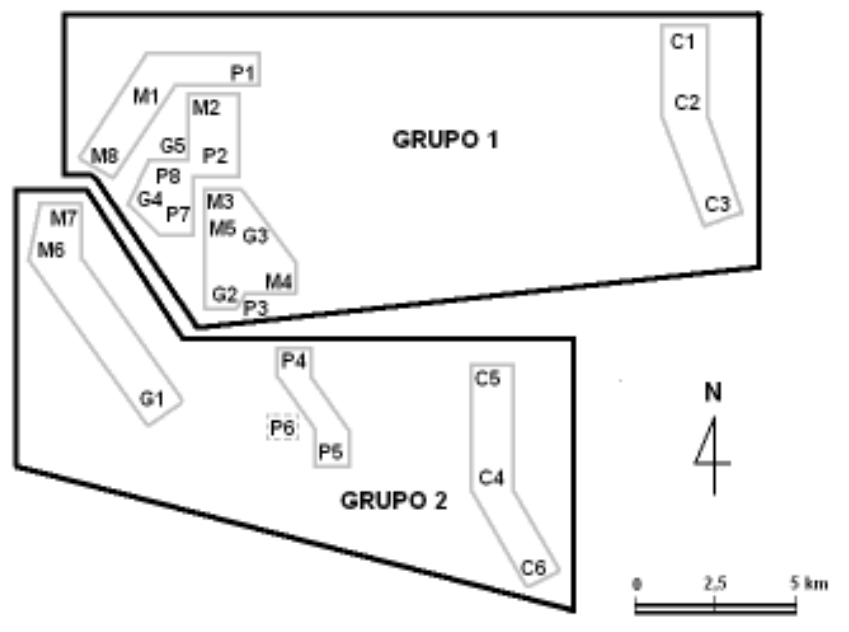

Figura 3. Grupos de fragmentos florestais da região do Planalto de Ibiúna, SP, resultantes da análise por TWINSPAN. Os códigos completos dos sítios são apresentados na Tab. 1. C - sítios localizados no interior da floresta contínua, Reserva Florestal do Morro Grande; G - fragmentos grandes (área superior a 50 ha); $\mathrm{M}$ - fragmentos médios (5 a 40 ha); $\mathrm{P}$ - fragmentos pequenos (2 a 5 ha). ( $-=$ Primeiro nível de divisão; $-=$ = Níveis inferiores de divisão; --- = Classificação duvidosa). deste grupo, duas características se destacam, em contraposição ao segundo grupo: há um número razoável de espécies que ocorrem também no cerradão ou na floresta estacional semidecidual (Chrysophyllum marginatum, Croton floribundus, Eugenia pluriflora, Gochnatia polymorpha, Lithraea molleoides, Nectandra grandiflora, Ocotea corymbosa e Vochysia tucanorum) e outras são espécies típicas da floresta ombrófila densa, mas geralmente heliófitas, pioneiras ou secundárias iniciais (Anadenanthera colubrina, Baccharis schultzii e Miconia sellowiana). São praticamente inexistentes, entre as espécies indicadoras desses sítios, aquelas típicas da floresta ombrófila densa em estádios avançados de sucessão.

No segundo grupo encontram-se oito sítios (e mais um de classificação duvidosa, considerado limítrofe dentro do primeiro grupo), localizados na face sul da região de estudo. Entre as espécies indicadas como preferenciais desses sítios encontram-se predominantemente espécies características da floresta ombrófila densa, especialmente umbrófilas, comuns em estádios sucessionais mais avançados, como Alibertia myrciifolia, Alsophila setosa, Bathysa meridionalis, Chionanthus filiformis, Euterpe edulis, Heisteria silvianii, e várias espécies climácicas das famílias Lauraceae e Myrtaceae.

Os níveis inferiores de divisão por TWINSPAN não revelam novos grupos que façam sentido ecológico. A semelhança florística entre os sub-grupos parece se estabelecer, sobretudo, em função da proximidade geográfica entre eles, o que é confirmado pelo teste 
de Mantel contrapondo as matrizes de distância geográfica e de similaridade florística entre sítios ( $\mathrm{p}=0,047$ no teste de Monte Carlo).

\section{Discussão}

Os resultados confirmaram a hipótese de que, dentro de uma mesma formação vegetal, comunidades em etapas paralelas do processo sucessional tendem a ter floras semelhantes. Por outro lado, refutou-se a hipótese de que a flora arbórea estaria também correlacionada com a estrutura da comunidade. Indiretamente, contatou-se que a evolução estrutural da floresta não acompanha, necessariamente, as mudanças florísticas esperadas ao longo da sucessão secundária.

Ainda que a semelhança florística entre as comunidades florestais estudadas também esteja associada à proximidade geográfica, este não foi o único e nem o mais importante dentre os fatores condicionantes de similaridade.

A existência de dois padrões distintos, ainda que sutis, correlacionados com a latitude, em uma região tão pequena (13,4 por $17,2 \mathrm{~km}$, em termos de latitude e longitude, respectivamente), sugere algumas explicações possíveis. A tomar pela flora característica (espécies indicadoras) de cada padrão, constata-se que essa é uma região com indícios de transição entre biomas, com a flora dos fragmentos e da Reserva do Morro Grande tendendo, ao sul, para a floresta ombrófila densa e, ao norte, para a floresta estacional semidecidual e o cerrado.

Estes resultados reforçam observações anteriores de que a flora desta região de Planalto apresenta características ecotonais de transição entre floresta ombrófila densa, floresta ombrófila mista, cerrado lato sensu e floresta estacional semidecidual (Eiten 1970; Nastri et al. 1992; Baitello et al. 1992; Salis et al. 1995; Aragaki \& Mantovani 1998; Albuquerque \& Rodrigues 2000; Catharino et al. 2006). Essas características ecotonais não parecem ligadas à heterogeneidade de solo e relevo, uma vez que a região é relativamente pequena e homogênea e ocupa uma faixa estreita de variação altitudinal (menos de $200 \mathrm{~m}$ de amplitude). Ademais, a heterogeneidade local do relevo não afeta a composição florística, conforme testado previamente por Silva et al. (dados não publicados). É possível que as características ecotonais da vegetação estejam atreladas à modificação relativamente abrupta nas características do clima que são observadas num gradiente SE-NW, à medida que aumenta a distância das escarpas da Serra de Paranapiacaba. Nesta região, observam-se climas do tipo $C f a, C f b, C w a$ ou $C w b$, i.e. temperado quente e úmido $(C), \operatorname{com}(w)$ ou sem $(f)$ período de seca, e com temperatura do mês mais quente acima $(a)$ ou abaixo (b) de $22^{\circ} \mathrm{C}$, segundo o sistema de classificação de Köppen (1948). Na região próxima à Serra, o clima tende a ser mais frio (em função da altitude) e úmido, com variação sazonal no regime de chuvas, porém sem déficit hídrico $(C f a)$. Em regiões mais distantes da Serra, em direção ao interior do estado, o clima tende a ficar mais quente $(C f b)$ e com estações secas e chuvosas mais bem marcadas, com ocorrência de déficit hídrico $(C w b)$.

Regiões de transição tendem a ter riqueza e diversidade elevadas, por abrigarem espécies oriundas de biomas distintos. De fato, na região de Ibiúna vem sendo observada não apenas uma alta riqueza florística, mas também um padrão de elevada riqueza para diferentes grupos de animais, como pequenos mamíferos, anfíbios e aranhas (Metzger et al. 2006b), o que faz com que essa região seja especialmente valiosa para conservação.

A indicação dos hotspots globais para conservação (Myers et al. 2000), no entanto, desconsidera as zonas ecotonais, centrando-se na área core dos biomas e, por isso mesmo, tem sido alvo de críticas (Smith et al. 2001; Scarano 2002). Uma vez que os pressupostos da indicação dos hotspots em escala global têm sido aplicados também em escalas regionais ou locais, as zonas de transição entre biomas, como é o caso da região estudada, tendem a ser sempre negligenciadas.

Atenção se deve ainda à circunstância de que, mediante um cenário de mudanças climáticas globais, essas zonas de transição são especialmente importantes no processo dinâmico de expansão e retração dos tipos vegetacionais (Scarano 2002; Durigan \& Ratter 2006). Todavia, o atual estado de fragmentação da paisagem nessa região impõe-se como um importante obstáculo para a ocorrência desses processos que, para ser vencido, pode depender de interferências de manejo visando ao restabelecimento do fluxo de pólen, sementes e agentes dispersores entre os fragmentos florestais remanescentes.

\section{Agradecimentos}

Os autores agradecem a Edivaldo Furlan e Viviane Soares Ramos, que muito contribuíram com os levantamentos de campo; à FAPESP, que, através 
do Programa BIOTA, proporcionou os recursos necessários para o desenvolvimento da pesquisa (processo n. 99/05123-4) e, especialmente, a dois revisores anônimos e ao editor de área de ecologia, Dr. Fabio R. Scarano, que, com seus comentários, em muito contribuíram para a versão final deste artigo.

\section{Referências bibliográficas}

Ab'Saber, A.N. 1992. A Serra do Japi, sua origem geomorfológica e a teoria dos refúgios. Pp. 12-23. In: L.P. Morellato (org.). Ecologia e preservação de uma área florestal no Sudeste do Brasil. Campinas, Editora da Unicamp/Fapesp.

Albuquerque, G.B. \& Rodrigues, R.R. 2000. A vegetação do Morro de Araçoiaba, Floresta Nacional de Iperó (SP). Scientia Forestalis 58: 145-159.

Almeida, F.F.M. 1964. Fundamentos geológicos do relevo paulista. São Paulo, Instituto Geográfico e Geológico.

Aragaki, S. \& Mantovani, W. 1998. Caracterização do clima e da vegetação de um remanescente florestal no Planalto Paulistano (SP). In: Anais do IV Simpósio de Ecossistemas Brasileiros. Águas de Lindóia, 1998. São Paulo, ACIESP. Publicação ACIESP 104: 25-36.

Baitello, J.B.; Aguiar, O.T.; Rocha, F.T.; Pastore, J.A. \& Esteves, R. 1992. Florística e fitossociologia do estrato arbóreo de um trecho da Serra da Cantareira (Núcleo Pinheirinho) - SP. Anais do $2^{\circ}$ Congresso Nacional sobre Essências Nativas. Revista do Instituto Florestal 4: 291-297 (Edição Especial).

Bernacci, L.C.; Franco, G.A.D.C.; Arbocz, G.; Catharino, E.L.; Durigan, G. \& Metzger, J.P. 2006. O efeito da fragmentação florestal na composição e riqueza de árvores na região da Reserva Morro Grande ( Planalto de Ibiúna ). Revista do Instituto Florestal 18: 121-166.

Catharino, E.L.; Bernacci, L.C.; Franco, G.A.D.C.; Durigan, G. \& Metzger, J.P. 2006. Aspectos da composição e diversidade do componente arbóreo das florestas da Reserva Florestal do Morro Grande, Cotia, SP. Biota Neotropica 6. http://www.biotaneotropica.org.br/v6n2/ pt/abstract?article+bn00306022006 (Acesso em: 3/05/2006).

Cottam, G. \& Curtis, J.T. 1956. The use of distance measures in phytosociological sampling. Ecology 37: 451-460.

Durigan, G. \& Ratter, J.A. 2006. Successional changes in cerrado and cerrado/forest ecotonal vegetation in western São Paulo State, Brazil, 1962-2000. Edinburgh Journal of Botany 63: 119-130.

Durigan, G.; Santos, J.D. \& Gandara, F.B. 2002. Fitossociologia de dois fragmentos de floresta estacional semidecidual no Pontal do Paranapanema, SP. Revista do Instituto Florestal 14: 13-26

Eiten, G. 1970. A vegetação do Estado de São Paulo. Boletim do Instituto de Botânica 7: 1-147.
Gandolfi, S.; Leitão Filho, H.F. \& Bezerra, C.L.F. 1995. Levantamento florístico e caráter sucessional das espécies arbustivo-arbóreas de uma floresta mesófila semidecídua no Município de Guarulhos, SP. Revista Brasileira de Biologia 55: 753-767.

Hill, M.O. 1979. TWINSPAN - a FORTRAN Program for Detrended Correspondence Analysis and Reciprocal Averaging. Ithaca, New York, Cornell University, Department of Ecology and Systematics.

Hill, M.O. \& Gauch, H.G. 1980. Detrended Correspondence Analysis, an improved ordination technique. Vegetatio 42: 47-58.

Ivanauskas, N.M.; Monteiro, R. \& Rodrigues, R.R. 2000. Similaridade florística entre áreas de floresta atlântica no Estado de São Paulo. Brazilian Journal of Ecology 1-2: 71-81.

Kageyama, P.Y. \& Viana, V.M. 1992. Tecnologia de sementes e grupos ecológicos de espécies arbóreas tropicais. Pp. 197-215. In: Anais do $2^{\mathbf{0}}$ Simpósio Brasileiro sobre Tecnologia de Sementes Florestais. Atibaia, 1989. São Paulo, Instituto Florestal (Série Documentos).

Köppen, W. 1948. Climatologia. Mexico City, Ed. Fondo Cultura Economica.

Kronka, F.J.N.; Nalon, M.A.; Matsukuma, C.K.; Kanashiro, M.M.; Ywane, M.S.S.; Pavão, M.; Durigan, G.; Lima, L.M.P.R.; Guillaumon, J.R.; Baitello, J.B.; Borgo, S.C.; Manetti, L.A.; Barradas, A.M.F.; Fukuda, J.C.; Shida, C.N.; Monteiro, C.H.B.; Pontinha, A.A.S.; Andrade, G.G.; Barbosa, O. \& Soares, A.P. 2005. Inventário Florestal da Vegetação Natural do Estado de São Paulo. São Paulo, Secretaria do Meio Ambiente / Instituto Florestal / Imprensa Oficial.

Mccune, B. \& Mefford, M.J. 1999. Ecological Diversity and its measurement. Princeton, NJ, Princeton University Press.

Metzger, J.P.; Alves, L.F.; Goulart, G.; Teixeira, A.M.G.; Simões, S.J.C. \& Catharino, E.L.M. 2006a. Uma área de relevante interesse biológico, porém pouco conhecida: a Reserva Florestal do Morro Grande. Biota Neotropica 6: http://www.biotaneotropica.org.br/v6n2/pt/ abstract?article+bn00406022006 (Acesso em: 3/05/2006).

Metzger, J.P.; Alves, L.F.; Pardini, R.; Dixo, M.; Nogueira, A.A.; Negrão, M.F.F.; Martensen, A.C. \& Catharino, E.L. 2006b. Características ecológicas e implicações para a conservação da Reserva Florestal do Morro Grande. Biota Neotropica 6: http://www.biotaneotropica.org.br/ v6n2/pt/abstract?article+bn00506022006 (Acesso em: 3/05/2006).

Myers, N.; Mittermeier, R.A.; Mitermeier, C.G.; Fonseca, G.A. \& Kent, J. 2000. Biodiversity hotspots for conservation priorities. Nature 403: $853-858$.

Nastri, V.D.F.; Catharino, E.L.M.; Rossi, L.; Barbosa, L.M.; Pirré, E.; Bedinelli, C.; Asperti, L.M.; Dorta, R.O. \& Costa, M.P. 1992. Estudos fitossociológicos em uma área do Instituto de Botânica de São Paulo utilizados em programas de educação ambiental. Revista do Instituto Florestal 4: 219-225. 
Oliveira Filho, A.T. \& Fontes, M.A. 2000. Patterns of floristic differentiation among Atlantic Forests em Southeastern Brazil and the influence of climate. Biotropica 32: 793-810.

Ponçano, W.L.; Carneiro, C.D.R.; Bistrichi, C.A.; Almeida, F.F.A. \& Prandini, F.L. 1981. Mapa geomorfológico do Estado de São Paulo. 1:1 000 000. São Paulo, IPT.

Salis, S.M.; Shepherd, G.J. \& Joly, C.A. 1995. Floristic comparison of mesophytic semideciduous forests of the interior of the state of São Paulo, Southeast Brazil. Vegetatio 119: 155-164.

Scarano, F.R. 2002. Structure, function and floristic relationships of plant communities in stressful habitats marginal to the Brazilin]na Atlantic Rainforest. Annals of Botany 90: 517-524.
Secretaria de Economia e Planejamento - SEP, 1979. Plano cartográfico do Estado de São Paulo, escala 1:10 000. Folhas SF-23-Y-C-V-2-SE-F, SF-23-Y-C-V-2-SE-F, SF-23Y-C-V-2-SE-E, SF-23-Y-C-V-4-NE-A, SF-23-Y-C-V-2-SE-D, SF-23-Y-C-V-4-NE-B, SF-23-Y-C-V-2-SE-C. São Paulo, Coordenadoria de Ação Regional, Divisão de Geografia, Governo do Estado de São Paulo.

Smith, T.B.; Klark, S.; Schneider, C.J.; Wayne, R.K. \& Moritz, C. 2001. Biodiversity hotspots and beyond: the need for preserving environmental transitions. Trends in Ecology and Evolution 16: 1-431.

Veloso, H.P.; Rangel Filho, A.L.R. \& Lima, J.C.A. 1991. Classificação da vegetação brasileira adaptada a um sistema universal. Rio de Janeiro, IBGE. 